\title{
Crack Formation in Metal Structures of Heavy Dump Trucks during Operation at Kuzbass Open Pit Mines
}

\author{
Andrey Pokatilov ${ }^{l}$, Anastasia Shirokolobova ${ }^{l}$, Roman Dobrynin ${ }^{l}$, and Andrey Vinidiktov ${ }^{l}$ \\ ${ }^{1}$ T.F. Gorbachev Kuzbass State Technical University, 650000, Kemerovo, 28 Vesennya St., the \\ Russian Federation
}

\begin{abstract}
The results of crack formation monitoring in metal structures of BelAZ heavy dump trucks during their operation at Kuzbass open-casts are given in the article. Possible causes and areas of the crack-like defects formation during operation of heave dump trucks at depths greater than $300 \mathrm{~m}$ are considered. The assembly units and elements of heave dump trucks and the areas of the highest total stresses are determined by solid modeling, strength analysis and monitoring of the condition of metal structures under production conditions. The law of crack length development in the areas of the transaxle-housing component and the fastening of the hydraulic cylinder depending on the number of loading cycles is established. The stresses dependence arising in the structural elements of heavy dump trucks during operation under various loads, on the number of loading cycles to failure, is presented.
\end{abstract}

\section{Introduction}

The operation of heavy dump trucks in difficult mining and geological conditions at Kuzbass open-casts shows that the choice of their main structural elements (suspension type, transmission and other assembly units), as well as changes in technical and economic indicators, are affected by operating conditions within the boundaries of the developed deposits [2]. Increased workloads that occur during transportation of rock mass influence on the elements of metal structures of dump trucks and lead to the appearance of crack-like defects of various shapes and sizes [3].

The purpose of this article is to highlight the problems of crack formation in the metal structures of dump trucks during operation at Kuzbass open-casts. For this reason, an attempt is made to analyse their stress state using the BelAZ-75131 model as an example based on monitoring of the occurrence of crack-like defects in the metal structures of heavy trucks. 


\section{Results and Discussions}

\subsection{Metal structures state analysis}

The monitoring of metal structure state of dump trucks of various carrying capacities using the methods of visual control and extensometry was carried out at open-casts of the North, Centre and South of Kuzbass in the period ща 2013-2016 (Fig. 1).

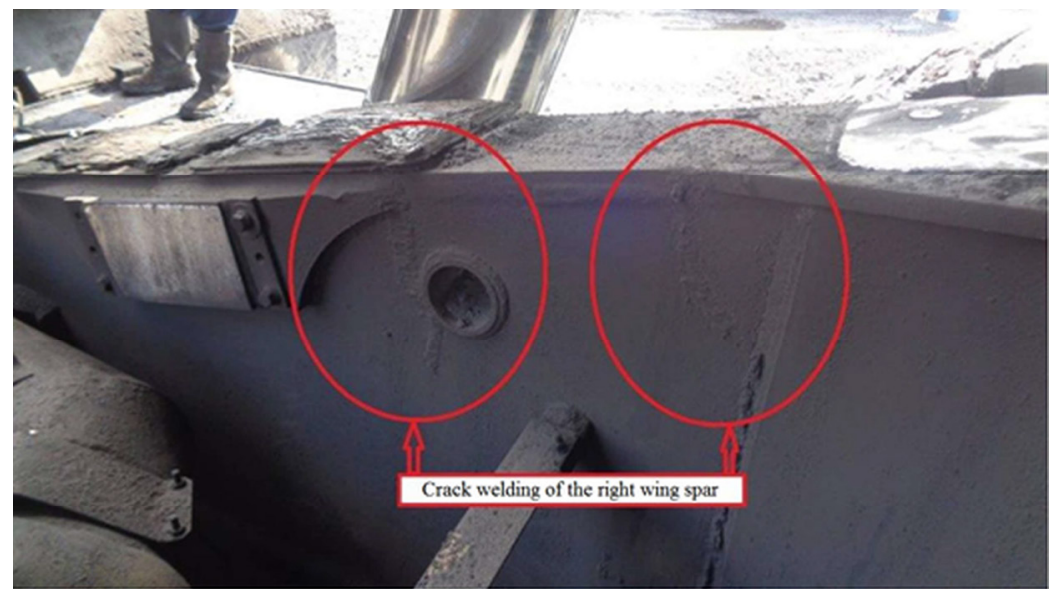

Fig. 1. Cracks in the frame of the BelAZ-75131 dump truck.

Complicated mining and geological and technological operating conditions of dump trucks lead to accumulation of fatigue damage at excessively large loads [4]. In this case, operational damages are epy consequence of their fatigue deformation, which various defects are represented by cracks, holes, breaks, bends, twisting, deformation etc. [6].

According to the results of statistical processing of the monitoring data, a diagram of the frequency appearance of crack-like defects in metal structures of dump trucks depending on geolocation of the deposit in Kemerovo region was constructed (Fig. 2).

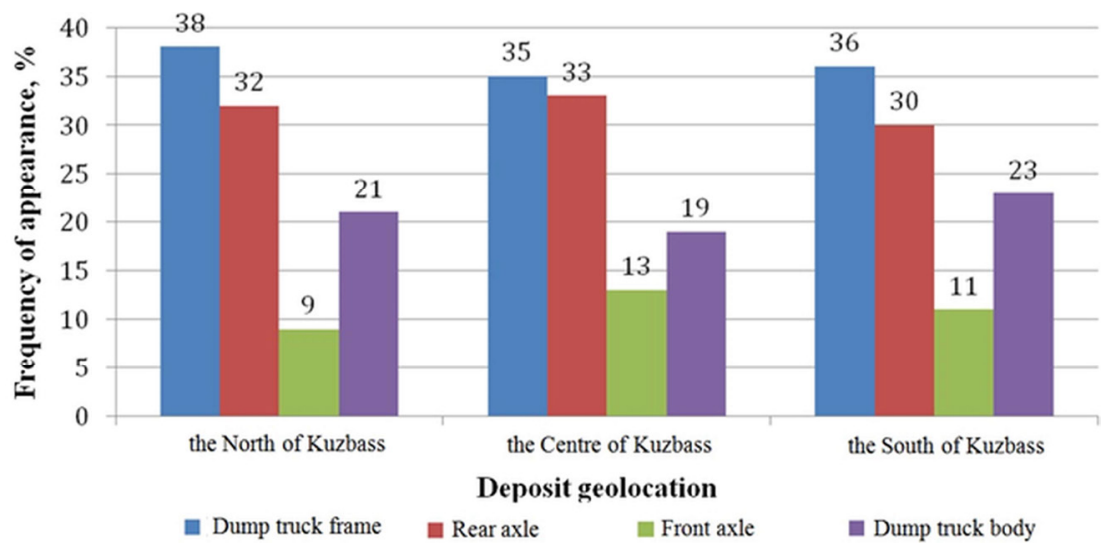

Fig. 2. The frequency of crack-like defects appearance in the dump trucks metal structures.

Figure 2 illustrates that most often cracks occur in truck frames and rear axles regardless of the location of the deposit being developed. The main reasons for their formation are the 
depth of deposit development, the quality of roads, slopes of technological roads, transportation distance, and quality of blasted rock mass, operational kilometres of a dump truck, the state of construction, climatic and other operating conditions.

The metal structures of dump trucks have static and dynamic loads during operation [7]. Static impacts include the own truck weight and the weight of transported blasted rock mass and mineral, the reaction of shock absorbers of a truck. When the truck moves along technological roads, as well as when it is loaded with rock mass by an excavator, the bearing metal structures are subjected to dynamic loading.

In the result of these studies, it was found that the greatest stresses in the metal structures of heavy vehicles occur in loading and driving modes. When loading metal structures of a frame and suspension are subjected to dynamic loading resulting from impact of unloaded rock mass. During the movement of a heavy truck along a career road, characterized by significant inequalities, the middle and cantilever body parts are the most loaded, as well as suspension elements experiencing flexure-torsion loads.

A more detailed analysis of the crack-like defect occurrence in the frames and rear axles of heavy dump trucks of BelAZ-75131 model during operation at Kuzbass open-casts allowed us to construct a bubble diagram of the effect of the depth of transporting rock mass on the size of defects (Fig. 3).

The blue bubbles were constructed according to statistics for the frames of heavy dump trucks of the BelAZ-75131 model, and red bubbles were built for the rear axles. The depth of the blasted rock mass transportation was taken vertically, which was ranked in three intervals: up to $150 \mathrm{~m}, 150300 \mathrm{~m}$ and over $300 \mathrm{~m}$. The length of the crack-like defects was taken horizontally, which was also ranked in three intervals: up to $25 \mathrm{~cm}, 2550 \mathrm{~cm}$ and over $50 \mathrm{~cm}$. The size of the bubbles corresponds to the frequency of crack-like defect occurrence of various size in certain operating conditions, where one of the main factors of crack formation is the depth of the developed deposit.

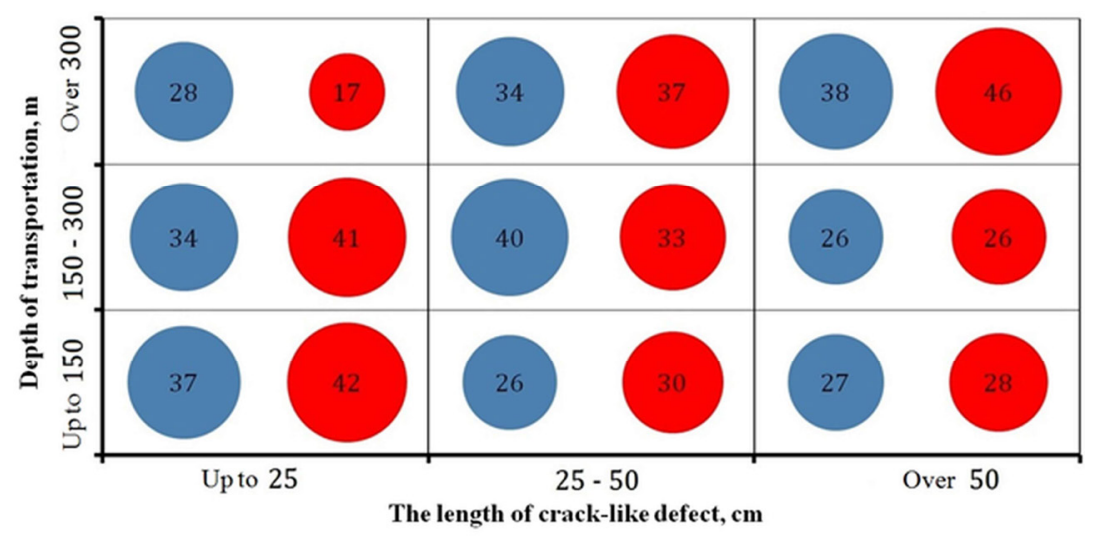

Fig. 3. The influence of the rock mass transportation depth on the size of the defects.

Fig. 3 shows that crack-like defects (the length of which in some places exceeds $50 \mathrm{~cm}$ ) more often occur in the metal structures of the rear axles, when BelAZ-75131 operates at depths greater than $300 \mathrm{~m}$. In this case, the defect can be emergency if its size reaches 50$60 \%$ of the size of structural element. An urgent issue is the determination of increased stress concentration centres in the metal structures of rear axles. 


\subsection{The study of the stress state of the rear axle BelAZ-75131}

Fig. 4 shows the rear axle of the BelAZ-75131 dump truck. Its main metal structures are made of steel 30L [5].

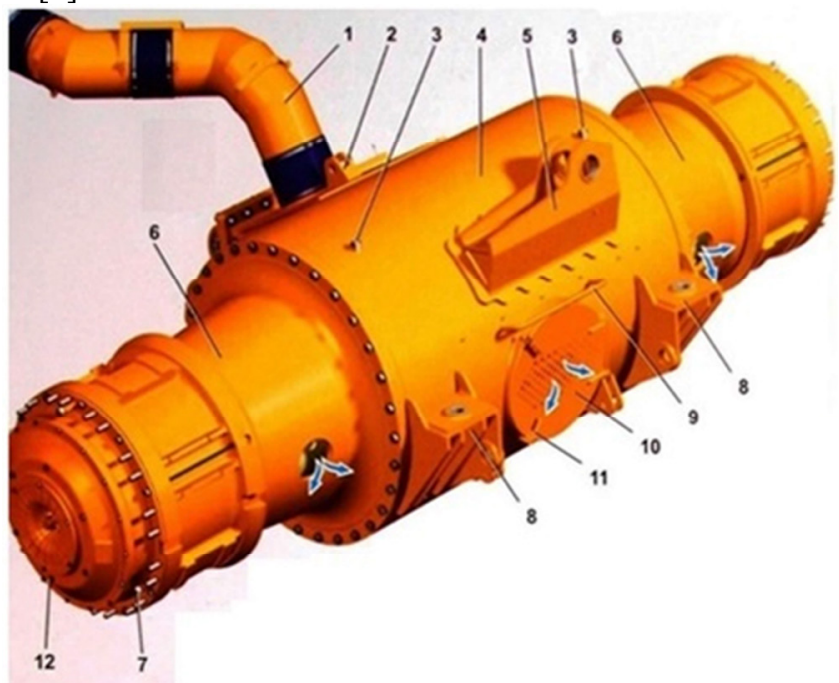

Fig. 4. The rear axle of the BelAZ 75131 dump truck [5] 1 - air duct; 2 - bracket group; 3 - limit stop; 4 - rear axle housing; 5 - attachment bracket of a cross-section bar and a suspension bracket of the back axle; 6 - in-wheel electric motor; 7 - drain plug; 8 - bracket group for cylinder suspension of the rear axle; 9 - handrail; 10 - manhole cover; 11, 16 - locking; 12 - control plug.

To study the stress state in the structural elements of the rear axle of a dump truck, a 3D model was developed in the ANSYS software package.

At each point of the beam of the rear axle of the truck, the stress components were determined numerically by creating a closed system consisting of static equations, physical equations and Cauchy equations.

To create a finite element model, the type of finite elements and the model characterizing the properties of the steel of which the structure is made were determined (Fig. 5). 


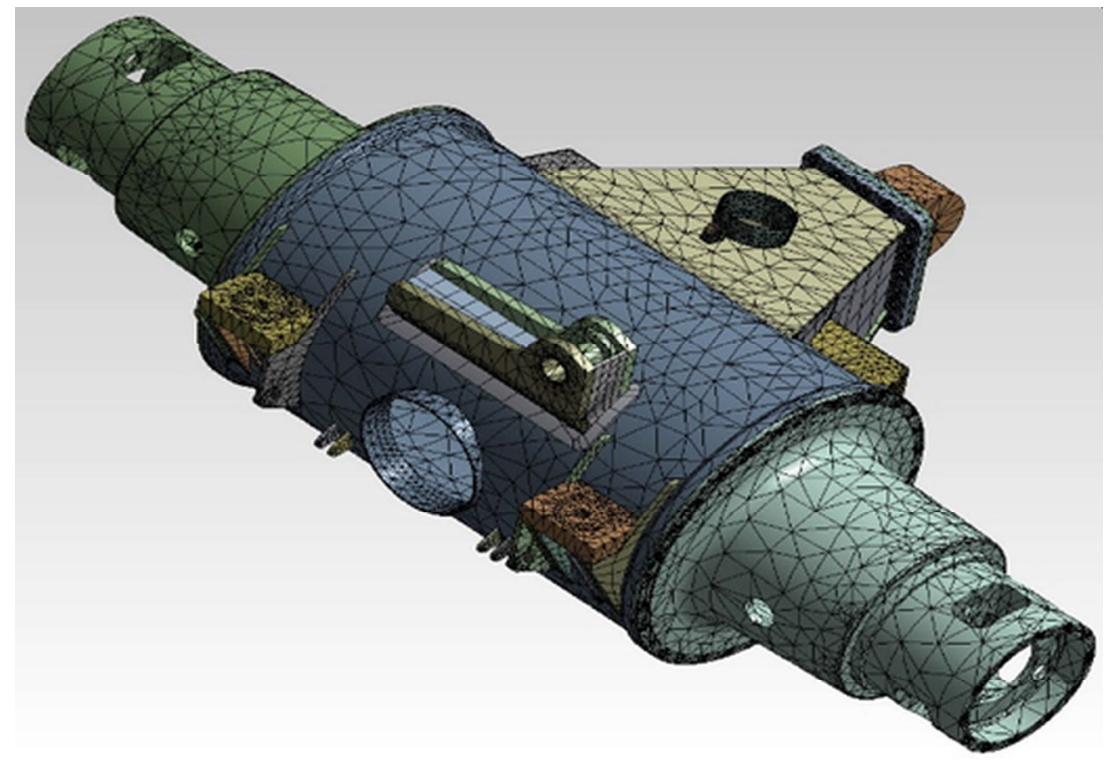

Fig. 5. The structure of the finite elements of the model in the ANSYS software package.

The length of the element did not exceed $1 \mathrm{~mm}$, the total number of nodes in the grid was 189613 , and there were 90546 elements.

Fig. 6 shows the design scheme with the fixing points and the place of current loads.

The table shows the data for calculating the stress state of the metal structures of the rear axle.

Table 1. The data for calculating the stress state.

\begin{tabular}{|c|c|}
\hline \multicolumn{2}{|c|}{ Input data } \\
\hline 1. Gross weight with load $(\mathrm{m}), \mathrm{kg}$ & 237000 \\
\hline 2. Permissible side rake $(\alpha){ }^{\circ}$ & 10 \\
\hline 3. Gearing ratio of gearbox wheel (u) & 19 \\
\hline $\begin{array}{c}\text { 4. Power of traction electric motor EK- } \\
\text { 420A (P), } \mathrm{kW}\end{array}$ & 420 \\
\hline $\begin{array}{c}\text { 5. Operational moment of the traction } \\
\text { electric motor EK-420A }(\mathrm{M}), \mathrm{N} \cdot \mathrm{m}\end{array}$ & 5984 \\
\hline 6. Tire outer diameter $(D), \mathrm{mm}$ & 3045 \\
\hline $\begin{array}{c}\text { 7. Centre of gravity displacement at side } \\
\text { rake }(a), \mathrm{mm}\end{array}$ & 250 \\
\hline $\begin{array}{c}\text { 8. The distance between the centres of the } \\
\text { track }(l), \mathrm{mm}\end{array}$ & 2210 \\
\hline 9. Body material & $\begin{array}{c}\text { Steel } \\
\text {. }\end{array}$ \\
\hline 10. Welded part material & Steel 20 \\
\hline
\end{tabular}




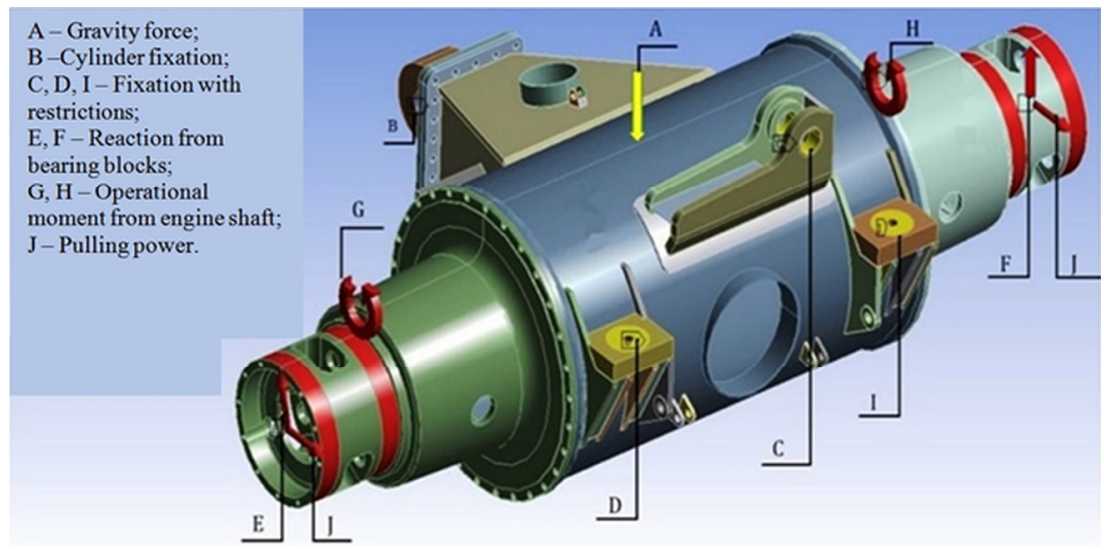

Fig. 6. The design scheme of the rear axle beam elements of the BelAZ-75131 dump truck.

The loads obtained by calculation affect only the formation of metal fatigue. Because of a large number of variable influences, centres of stress concentration occur, resulting in the growth of macrocracks in the material, which lead to complete destruction [1].

Strength analysis during solid-state modeling made it possible to establish that the areas of increased stress concentration in the elements of the rear axles of automobiles are attachment points, a crankcase and an air distribution box (Fig. 7).

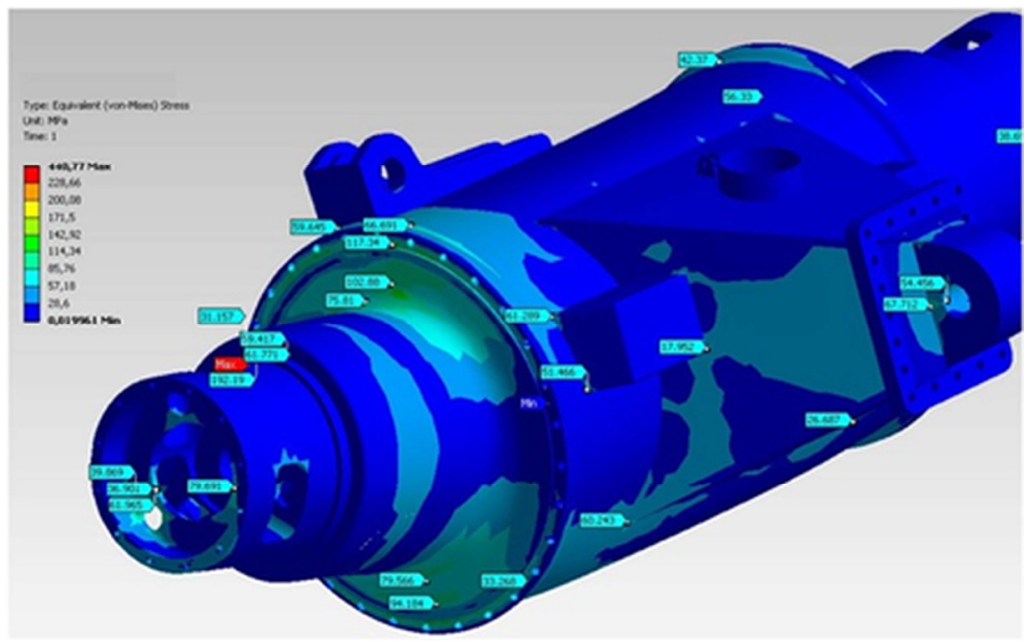

Fig. 7. Solid-state modeling of the rear axle beam of the BelAZ-75131 dump truck.

Figure 7 shows that the values of the total stresses reach approximately $240 \mathrm{MPa}$, arising in the area of the junction of the electric motor-wheel casing and the rear axle housing, as well as in the area of attachment of the suspension cylinder-firewood. 


\subsection{Result analysis}

The results of the stress state calculation and crack formation monitoring in the composite node of the rear axle of the suspension "crankcase - hydraulic cylinder fastening" made it possible to establish the law of crack growth in it:

$$
\frac{d l}{d N}=8.7 \cdot 10^{-14}(\Delta K)^{3.5},
$$

where $l-$ is crack length; $N-$ is the number of load application cycles; $\Delta K$ - is a range of stress intensity factor; $8.7 \cdot 10^{-1}$ and 3.5 - are empirical material constants.

Taking into account the geometrical features of the element, stress state parameters and material properties, the crack growth equation can be written as:

$$
l_{\mathrm{cl}}=\left(5.26-2.7 \cdot 10^{-5} \cdot N\right)^{-1.33} \text {. }
$$

Using the obtained durability indicators, a diagram of the effect of the number of loading cycles to failure on the values of stresses arising during operation was built (Fig. 8).

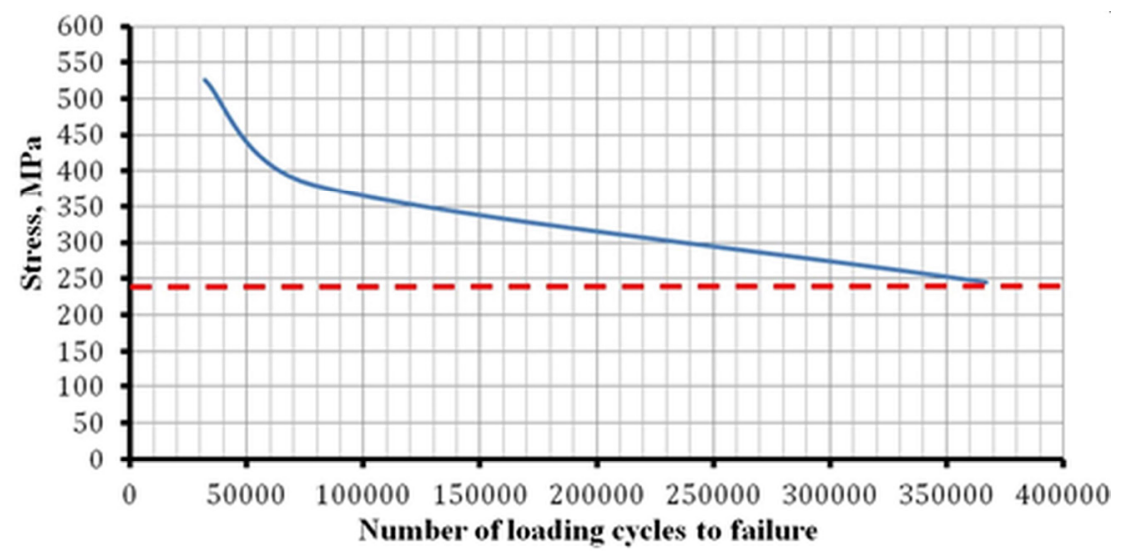

Fig. 8. Dependence of arising stresses on loading cycles.

The durability limit for steel 30L, which the rear axle housing units are made of, is 215 $\mathrm{MPa}$. According to regulatory standards, the number of loading cycles to failure is $10^{6}$ in the case when the operational stresses in the metal structures do not exceed the endurance limit.

The dashed line indicates the stress of $240 \mathrm{MPa}$, obtained by the results of static calculation. In this case, the number of loading cycles to failure will not exceed 370,000; it means that the lifespan of the suspension metal structures is reduced by more than 2 times.

The operation of heavy dump trucks in Kuzbass open casts is carried out in difficult mining and technological conditions, and constantly changing factors that affect the stresses equivalent in metal structures have a significant impact on changing the magnitude of loading cycles to failure of the metal structures of the rear axle. The equation obtained by approximating the results of the study allows to set the desired variable:

$$
N=1 \cdot 10^{14} M_{\sigma a}^{-3.52},
$$


where $N$ - is the number of loading cycles to failure of the metal structures of the rear axle; $M_{\sigma a}$ - is mathematical expectation of stress amplitude, MPa.

The approximation coefficient does not exceed 0.97 . The number of cycles to failure can be determined using the obtained dependence in the operational solution of operational problems.

\section{Conclusion}

Operational impacts on the metal structures of heavy dump trucks when driving on open cast and technological roads determine the stress values in the suspension elements, which often exceed the endurance limit. The result of their occurrence is the formation and growth of micro- and macro cracks, progressing and destroying structural elements.

The development of Kuzbass deposits at great depths makes it difficult to use other type of transport except automobile for transportation of blasted rock mass. Reducing the frequency of crack-like defects occurrence of emergency sizes in the elements of the rear axles of heavy dump trucks during operation at depths greater than $300 \mathrm{~m}$ will reduce downtime and the cost of repair work, save the lifespan of metal structures and increase the volume of mining.

\section{Reference}

1. I. A. Panachev, I. V. Kuznetsov, Journal of Mining Science, 51, 267 (2015)

2. Baoying Fan, Yingju Yuan, International Journal of Mining Science and Technology, 26, 653 (2016)

3. I. A. Panachev, G. V. Shirokolobov, I. V. Kuznetsov, A. G. Shirokolobova, The 8th Russian-Chinese Symposium. Coal in the 21st Century: Mining, Processing and Safety, 1 (2016)

4. A. Soofastaei, S.M. Aminossadati, M.S. Kizil, P. Knights, International Journal of Mining Science and Technology, 26, 745 (2016)

5. I. V. Sokolov, A. A. Smirnov, Yu. G. Antipin, K. V. Baranovskii, Journal of Mining Science, 52, 121 (2016)

6. V. A. Solomennikov, V. I. Cheskidov, Journal of Mining Science, 51, 1213 (2015)

7. S. V. Klishin, A. F. Revuzhenko, Journal of Mining Science, 51, 1070 (2015)

8. Chengguo Zhang, Ismet Canbulat, Faham Tahmasebinia, Bruce Hebblewhite, International Journal of Mining Science and Technology, 27, 43 (2017)

9. Fukun Xiao, Gang Liu, Ze Zhang, Zhiliang Shen, Fengrui Zhang, Yifei Wang, International Journal of Mining Science and Technology, 26, 981 (2016)

10. Jingdong Jiang, Quansheng Liu, Jie Xu, International Journal of Mining Science and Technology, 26, 1003, 2016.

11. Jesse W. Puller, Ken W. Mills, Rob G. Jeffrey, Rick J. Walker, International Journal of Mining Science and Technology, 26, 103 (2016)

12. V. P. Efimov, Journal of Mining Science, 52, 274 (2016)

13. S. A. Bornyakov, D. V. Salko, Journal of Mining Science, 52, 338 (2016)

14. S. A. Prokopenko, V. S. Ludzish, I. A. Kurzina, Journal of Mining Science, 52, 153 (2016) 
15. E. N. Sher, V. P. Efimov, Journal of Mining Science, 51, 1108 (2015) 